\title{
The Existence and Uniqueness of Coupled Best Proximity Point for Proximally Coupled Contraction in a Complete Ordered Metric Space
}

\author{
V. Pragadeeswarar, ${ }^{1}$ M. Marudai, ${ }^{1}$ P. Kumam, ${ }^{2}$ and K. Sitthithakerngkiet ${ }^{3}$ \\ ${ }^{1}$ Department of Mathematics, Bharathidasan University, Tiruchirappalli, Tamil Nadu 620 024, India \\ ${ }^{2}$ Department of Mathematics, Faculty of Science, King Mongkut's University of Technology Thonburi (KMUTT), Bang Mod, \\ Thung Khru, Bangkok 10140, Thailand \\ ${ }^{3}$ Department of Mathematics, Faculty of Applied Science, King Mongkut's University of North Bangkok (KMUTNB), Wongsawang, \\ Bangsue, Bangkok 10800, Thailand
}

Correspondence should be addressed to P. Kumam; poom.kum@kmutt.ac.th and K. Sitthithakerngkiet; kanokwans@kmutnb.ac.th Received 2 February 2014; Accepted 18 April 2014; Published 14 May 2014

Academic Editor: Salvador Romaguera

Copyright (C) 2014 V. Pragadeeswarar et al. This is an open access article distributed under the Creative Commons Attribution License, which permits unrestricted use, distribution, and reproduction in any medium, provided the original work is properly cited.

We prove the existence and uniqueness of coupled best proximity point for mappings satisfying the proximally coupled contraction in a complete ordered metric space. Further, our result provides an extension of a result due to Bhaskar and Lakshmikantham.

\section{Introduction}

One of the most useful tools in the study of nonlinear functional equation is to describe many problems in physics, chemistry, and engineering. It can be formulated in terms of finding the fixed points of a nonlinear self-mapping. Fixed point theory investigates the techniques for determining a solution of the pattern $T x=x$, where $T$ is a self-mapping defined on a subset $A$ of a metric space $X$. Noteworthy, a fixed point $x$ of $T$ on can be written by $d(x, T x)=0$.

A well-known principle that guarantees a unique fixed point solution is the Banach contraction principle [1] which states on a complete metric space $X$ for a contraction selfmapping (i.e., $d(T x, T y) \leq \alpha d(x, y)$ for all $x, y \in X$, where $\alpha$ is a nonnegative number such that $\alpha<1$ ). Over the years, this principle has been generalized in many ways; see also [2-6]. Recently, an interesting way is to study the extension of Banach contraction principle to the case of nonself-mappings. Certainly, a contraction non-self-mapping $T$ : $A \rightarrow B$ does not necessarily have a fixed point, where $A$ and $B$ are nonempty subsets of a metric space $X$.

Ultimately, one proceeds to find an approximate solution $x \in A$ which is closest to $T x$ in the sense that distance $d(x, T x)$ is minimum which implies that $x$ and $T x$ are in close proximity to each other. Indeed, the best approximation theorems and the best proximity point theorem investigate the existence of an approximate solution to fixed point problems for the non-self- mappings. In 1969, Fan [7] guarantees at least one solution to the minimization problem $\min _{x \in A}\|x-T x\|$, where $A$ is a nonempty compact convex subset of a normed linear space $X$ and $T: A \rightarrow X$ is a continuous function. Such an element $x \in A$ satisfying the above condition is called a best approximant of $T$ in $A$. Note that if $x \in A$ is a best approximant, then $\|x-T x\|$ need not be the optimum. As a matter of fact, the best proximity point theorems have been explored to find sufficient conditions for the existence of an element $x$ such that the error $d(x, T x)$ is minimum.

To have a concrete lower bound, let us consider two nonempty subsets $A, B$ of a metric space $X$ and a mapping $T: A \rightarrow B$. The natural question is whether one can find an element $x^{*} \in A$ such that $d\left(x^{*}, T x^{*}\right)=d(A, B)$, where $d(A, B):=\min \{d(x, T x): x \in A\}$. Since $d(x, T x) \geq d(A, B)$ for all $x \in A$, the optimal solution to the problem of minimizing the real valued function $x \rightarrow d(x, T x)$ over the domain $A$ of the mapping $T$ will be the one for which the value $d(A, B)$ is attained. A point that satisfies the condition 
$d(x, T x)=d(A, B)$ is called a best proximity point of $T$. Furthermore, the best proximity theorems also regress to an extension of fixed point theorem; that is, a best proximity point becomes a fixed point if either $d(A, B)=0$ or the mapping under consideration is a self-mapping.

The existence and convergence of best proximity points are an interesting topic of optimization theory. For more details on this approach, we refer the reader to De la Sen and Agarwal [8], Kumam et al. [9-11], di Bari et al. [12], Eldred and Veeramani [13], Al-Thagafi and Shahzad [14], Sadiq Basha and Veeramani [15], Kim and Lee [16], Kirk et al. [17], Sankar Raj [18], Karapınar et al. [19], and Jleli and Samet [20]. The study of best proximity point in the setting of partially ordered metric space attracted recently the attention of many authors; see [21-33].

Now we recall the definition of coupled fixed point. Let $X$ be a nonempty set and $F: X \times X \rightarrow X$ a given mapping. An element $(x, y) \in X \times X$ is called a coupled fixed point of the mapping $F$ if $F(x, y)=x$ and $F(y, x)=y$. In 2006, Bhaskar and Lakshmikantham [34] proved some coupled fixed point theorems for mappings satisfying the mixed monotone mapping. Indeed, let $(X, \leq)$ be a partially ordered set; the mapping $F$ is said to have the mixed monotone property if

$$
\begin{array}{r}
x_{1}, x_{2} \in X, \quad x_{1} \leq x_{2} \Longrightarrow F\left(x_{1}, y\right) \leq F\left(x_{2}, y\right), \\
\forall y \in X, \\
y_{1}, y_{2} \in X, \quad y_{1} \leq y_{2} \Longrightarrow F\left(x, y_{1}\right) \geq F\left(x, y_{2}\right), \\
\forall x \in X .
\end{array}
$$

Their results investigate a large class of problems and show the existence and uniqueness of a solution for a periodic boundary value problem. For more details on this concept one may go through the references [35-37].

Motivated by the above theorems, we introduce the concept of proximally mixed monotone property and proximally coupled contraction. We also explore the existence and uniqueness of coupled best proximity points in the setting of partially ordered metric spaces, thereby producing optimal approximate solutions for that function with respect to both coordinates. Further, we attempt to give the generalization of the results in [34].

\section{Preliminaries}

Let $X$ be a nonempty set such that $(X, d)$ is a metric space. Unless otherwise specified, it is assumed throughout this section that $A$ and $B$ are nonempty subsets of the metric space $(X, d)$; the following notions are used subsequently:

$$
\begin{gathered}
d(A, B):=\inf \{d(x, y): x \in A, y \in B\}, \\
A_{0}=\{x \in A: d(x, y)=d(A, B) \text { for some } y \in B\}, \\
B_{0}=\{y \in B: d(x, y)=d(A, B) \text { for some } x \in A\} .
\end{gathered}
$$

In [17], the authors discussed sufficient conditions which guarantee the nonemptiness of $A_{0}$ and $B_{0}$. Also, in [15], the authors proved that $A_{0}$ is contained in the boundary of $A$. Moreover, the authors proved that $A_{0}$ is contained in the boundary of $A$ in the setting of normed linear spaces.

Definition 1 . Let $(X, d, \leq)$ be a partially ordered metric space and $A, B$ nonempty subsets of $X$. A mapping $F: A \times$ $A \rightarrow B$ is said to have proximal mixed monotone property if $F(x, y)$ is proximally nondecreasing in $x$ and is proximally nonincreasing in $y$; that is, for all $x, y \in A$,

$$
\begin{aligned}
& \left.\begin{array}{r}
x_{1} \leq x_{2} \\
d\left(u_{1}, F\left(x_{1}, y\right)\right)=d(A, B) \\
d\left(u_{2}, F\left(x_{2}, y\right)\right)=d(A, B)
\end{array}\right\} \Longrightarrow u_{1} \leq u_{2} \\
& \left.\begin{array}{r}
y_{1} \leq y_{2} \\
d\left(u_{3}, F\left(x, y_{1}\right)\right)=d(A, B) \\
d\left(u_{4}, F\left(x, y_{2}\right)\right)=d(A, B)
\end{array}\right\} \Longrightarrow u_{4} \leq u_{3},
\end{aligned}
$$

where $x_{1}, x_{2}, y_{1}, y_{2}, u_{1}, u_{2}, u_{3}, u_{4} \in A$.

One can see that, if $A=B$ in the above definition, the notion of proximal mixed monotone property reduces to that of mixed monotone property.

Lemma 2. Let $(X, d, \leq)$ be a partially ordered metric space and $A, B$ nonempty subsets of $X$. Assume that $A_{0}$ is nonempty. $A$ mapping $F: A \times A \rightarrow B$ has proximal mixed monotone property with $F\left(A_{0} \times A_{0}\right) \subseteq B_{0}$; then for any $x_{0}, x_{1}, x_{2}, y_{0}$, $y_{1}$ in $A_{0}$

$$
\left.\begin{array}{cr}
x_{0} \leq x_{1}, & y_{0} \geq y_{1} \\
d\left(x_{1}, F\left(x_{0}, y_{0}\right)\right)= & d(A, B) \\
d\left(x_{2}, F\left(x_{1}, y_{1}\right)\right)=d(A, B)
\end{array}\right\} \Longrightarrow x_{1} \leq x_{2} .
$$

Proof. By hypothesis $F\left(A_{0} \times A_{0}\right) \subseteq B_{0}, F\left(x_{1}, y_{0}\right) \in B_{0}$. Hence there exists $x_{1}^{*} \in A$ such that

$$
d\left(x_{1}^{*}, F\left(x_{1}, y_{0}\right)\right)=d(A, B) .
$$

Using $F$ is proximal mixed monotone (in particular $F$ is proximally nondecreasing in $x$ ) to (4) and (5), we get

$$
\left.\begin{array}{r}
x_{0} \leq x_{1} \\
d\left(x_{1}, F\left(x_{0}, y_{0}\right)\right)=d(A, B) \\
d\left(x_{1}^{*}, F\left(x_{1}, y_{0}\right)\right)=d(A, B)
\end{array}\right\} \Longrightarrow x_{1} \leq x_{1}^{*}
$$

Analogously, using $F$ is proximal mixed monotone (in particular $F$ is proximally nonincreasing in $y$ ) to (4) and (5), we get

$$
\left.\begin{array}{r}
y_{1} \leq y_{0} \\
d\left(x_{2}, F\left(x_{1}, y_{1}\right)\right)=d(A, B) \\
d\left(x_{1}^{*}, F\left(x_{1}, y_{0}\right)\right)=d(A, B)
\end{array}\right\} \Longrightarrow x_{1}^{*} \leq x_{2}
$$

From (6) and (7), one can conclude that $x_{1} \leq x_{2}$. Hence the proof is completed.

Lemma 3. Let $(X, d, \leq)$ be a partially ordered metric space and $A, B$ nonempty subsets of $X$. Assume that $A_{0}$ is nonempty. $A$ mapping $F: A \times A \rightarrow B$ has proximal mixed monotone 
property with $F\left(A_{0} \times A_{0}\right) \subseteq B_{0}$; then for any $x_{0}, x_{1}, y_{0}, y_{1}$, $y_{2}$ in $A_{0}$

$$
\left.\begin{array}{cr}
x_{0} \leq x_{1}, & y_{0} \geq y_{1} \\
d\left(y_{1}, F\left(y_{0}, x_{0}\right)\right)= & d(A, B) \\
d\left(y_{2}, F\left(y_{1}, x_{1}\right)\right)= & d(A, B)
\end{array}\right\} \Longrightarrow y_{1} \geq y_{2} .
$$

Proof. The proof is same as Lemma 2.

Definition 4 . Let $(X, d, \leq)$ be a partially ordered metric space and $A, B$ nonempty subsets of $X$. A mapping $F: A \times A \rightarrow$ $B$ is said to be proximally coupled contraction if there exists $k \in(0,1)$ such that whenever

$$
\begin{aligned}
\left.\begin{array}{c}
x_{1} \leq x_{2}, \\
y_{1} \geq y_{2} \\
d\left(u_{1}, F\left(x_{1}, y_{1}\right)\right)= \\
d(A, B) \\
d\left(u_{2}, F\left(x_{2}, y_{2}\right)\right)=d(A, B)
\end{array}\right\} & \Rightarrow d\left(u_{1}, u_{2}\right) \\
& \leq \frac{k}{2}\left[d\left(x_{1}, x_{2}\right)+d\left(y_{1}, y_{2}\right)\right]
\end{aligned}
$$

where $x_{1}, x_{2}, y_{1}, y_{2}, u_{1}, u_{2} \in A$.

One can see that, if $A=B$ in the above definition, the notion of proximally coupled contraction reduces to that of coupled contraction.

\section{Coupled Best Proximity Point Theorems}

Let $(X, d, \leq)$ be a partially ordered complete metric space endowed with the product space $X \times X$ with the following partial order:

$$
\begin{gathered}
\text { for }(x, y),(u, v) \in X \times X, \\
(u, v) \leq(x, y) \Longleftrightarrow x \geq u, y \leq v .
\end{gathered}
$$

Theorem 5. Let $(X, \leq, d)$ be a partially ordered complete metric space. Let $A$ and $B$ be nonempty closed subsets of the metric space $(X, d)$ such that $A_{0} \neq \emptyset$. Let $F: A \times A \rightarrow B$ satisfy the following conditions.

(i) $F$ is a continuous proximally coupled contraction having the proximal mixed monotone property on $A$ such that $F\left(A_{0} \times A_{0}\right) \subseteq B_{0}$.

(ii) There exist elements $\left(x_{0}, y_{0}\right)$ and $\left(x_{1}, y_{1}\right)$ in $A_{0} \times A_{0}$ such that

$$
\begin{aligned}
& d\left(x_{1}, F\left(x_{0}, y_{0}\right)\right)=d(A, B) \text { with } x_{0} \leq x_{1}, \\
& d\left(y_{1}, F\left(y_{0}, x_{0}\right)\right)=d(A, B) \text { with } y_{0} \geq y_{1} .
\end{aligned}
$$

Then there exist $(x, y) \in A \times A$ such that $d(x, F(x, y))=$ $d(A, B)$ and $d(y, F(y, x))=d(A, B)$.

Proof. By hypothesis there exist elements $\left(x_{0}, y_{0}\right)$ and $\left(x_{1}, y_{1}\right)$ in $A_{0} \times A_{0}$ such that

$$
\begin{aligned}
& d\left(x_{1}, F\left(x_{0}, y_{0}\right)\right)=d(A, B) \quad \text { with } x_{0} \leq x_{1}, \\
& d\left(y_{1}, F\left(y_{0}, x_{0}\right)\right)=d(A, B) \quad \text { with } y_{0} \geq y_{1} .
\end{aligned}
$$

Because of the fact that $F\left(A_{0} \times A_{0}\right) \subseteq B_{0}$, there exists an element $\left(x_{2}, y_{2}\right)$ in $A_{0} \times A_{0}$ such that

$$
\begin{aligned}
& d\left(x_{2}, F\left(x_{1}, y_{1}\right)\right)=d(A, B), \\
& d\left(y_{2}, F\left(y_{1}, x_{1}\right)\right)=d(A, B) .
\end{aligned}
$$

Hence from Lemmas 2 and 3, we obtain $x_{1} \leq x_{2}$ and $y_{1} \geq y_{2}$.

Continuing this process, we can construct the sequences $\left(x_{n}\right)$ and $\left(y_{n}\right)$ in $A_{0}$ such that

$$
d\left(x_{n+1}, F\left(x_{n}, y_{n}\right)\right)=d(A, B), \quad \forall n \in \mathbb{N}
$$

with $x_{0} \leq x_{1} \leq x_{2} \leq \cdots x_{n} \leq x_{n+1} \cdots$ and

$$
d\left(y_{n+1}, F\left(y_{n}, x_{n}\right)\right)=d(A, B), \quad \forall n \in \mathbb{N}
$$

with $y_{0} \geq y_{1} \geq y_{2} \geq \cdots y_{n} \geq y_{n+1} \cdots$.

Then $d\left(x_{n}, F\left(x_{n-1}, y_{n-1}\right)\right)=d(A, B), d\left(x_{n+1}, F\left(x_{n}, y_{n}\right)\right)=$ $d(A, B)$ and also we have $x_{n-1} \leq x_{n}, y_{n-1} \geq y_{n}, \forall n \in \mathbb{N}$. Now using that $F$ is proximally coupled contraction on $A$ we get

$$
d\left(x_{n}, x_{n+1}\right) \leq \frac{k}{2}\left[d\left(x_{n-1}, x_{n}\right)+d\left(y_{n-1}, y_{n}\right)\right], \quad \forall n \in \mathbb{N} .
$$

Similarly

$$
d\left(y_{n}, y_{n+1}\right) \leq \frac{k}{2}\left[d\left(y_{n-1}, y_{n}\right)+d\left(x_{n-1}, x_{n}\right)\right], \quad \forall n \in \mathbb{N} .
$$

Adding (16) and (17), we get

$$
\begin{aligned}
& d\left(x_{n}, x_{n+1}\right)+d\left(y_{n}, y_{n+1}\right) \\
& \quad \leq k\left[d\left(x_{n-1}, x_{n}\right)+d\left(y_{n-1}, y_{n}\right)\right] \\
& \quad \leq k\left[k\left[d\left(x_{n-2}, x_{n-1}\right)+d\left(y_{n-2}, y_{n-1}\right)\right]\right] \\
& \quad \leq \cdots \\
& \quad \leq k^{n}\left[d\left(x_{0}, x_{1}\right)+d\left(y_{0}, y_{1}\right)\right] .
\end{aligned}
$$

Finally, we get

$$
d\left(x_{n}, x_{n+1}\right)+d\left(y_{n}, y_{n+1}\right) \leq k^{n}\left[d\left(x_{0}, x_{1}\right)+d\left(y_{0}, y_{1}\right)\right] .
$$

Now we prove that $\left(x_{n}\right)$ and $\left(y_{n}\right)$ are Cauchy sequences.

For $n>m$, regarding triangle inequality and (19), one can observe that

$$
\begin{aligned}
& d\left(x_{n}, x_{m}\right)+d\left(y_{n}, y_{m}\right) \\
& \leq d\left(x_{n}, x_{n-1}\right)+d\left(y_{n}, y_{n-1}\right)+\cdots+d\left(x_{m}, x_{m+1}\right) \\
&+d\left(y_{m}, y_{m+1}\right) \\
& \leq\left(k^{n-1}+\cdots+k^{m}\right)\left[d\left(x_{0}, x_{1}\right)+d\left(y_{0}, y_{1}\right)\right] \\
& \leq \frac{k^{m}}{1-k}\left[d\left(x_{0}, x_{1}\right)+d\left(y_{0}, y_{1}\right)\right] .
\end{aligned}
$$


Let $\epsilon>0$ be given. Choose a natural number $M$ such that $\left(k^{m} /(1-k)\right)\left[d\left(x_{0}, x_{1}\right)+d\left(y_{0}, y_{1}\right)\right]<\epsilon$ for all $m>M$. Thus, $d\left(x_{n}, x_{m}\right)+d\left(y_{n}, y_{m}\right)<\epsilon$ for $n>m$. Therefore, the sequences $\left(x_{n}\right)$ and $\left(y_{n}\right)$ are Cauchy.

Since $A$ is closed subset of a complete metric space $X$, these sequences have limits. Thus, there exists $x, y \in A$ such that $x_{n} \rightarrow x$ and $y_{n} \rightarrow y$. Therefore $\left(x_{n}, y_{n}\right) \rightarrow(x, y)$ in $A \times$ $A$. Since $F$ is continuous, we have $F\left(x_{n}, y_{n}\right) \rightarrow F(x, y)$ and $F\left(y_{n}, x_{n}\right) \rightarrow F(y, x)$.

Hence the continuity of the metric function $d$ implies that $d\left(x_{n+1}, F\left(x_{n}, y_{n}\right)\right) \rightarrow d(x, F(x, y))$ and $d\left(y_{n+1}, F\left(y_{n}, x_{n}\right)\right) \rightarrow d(y, F(y, x))$. But from (14) and (15) we get that the sequences $d\left(x_{n+1}, F\left(x_{n}, y_{n}\right)\right)$ and $d\left(y_{n+1}, F\left(y_{n}, x_{n}\right)\right)$ are constant sequences with the value $d(A, B)$. Therefore, $d(x, F(x, y))=d(A, B)$ and $d(y, F(y, x))=d(A, B)$. This completes the proof of the theorem.

Corollary 6. Let $(X, \leq, d)$ be a partially ordered complete metric space. Let $A$ be nonempty closed subset of the metric space $(X, d)$. Let $F: A \times A \rightarrow A$ satisfy the following conditions.

(i) $F$ is continuous having the proximal mixed monotone property and proximally coupled contraction on $A$.

(ii) There exist $\left(x_{0}, y_{0}\right)$ and $\left(x_{1}, y_{1}\right)$ in $A \times A$ such that $x_{1}=$ $F\left(x_{0}, y_{0}\right)$ with $x_{0} \leq x_{1}$ and $y_{1}=F\left(y_{0}, x_{0}\right)$ with $y_{0} \geq$ $y_{1}$.

Then there exist $(x, y) \in A \times A$ such that $d(x, F(x, y))=0$ and $d(y, F(y, x))=0$.

In what follows we prove that Theorem 5 is still valid for $F$ not necessarily continuous, assuming the following hypothesis in $A$ :

$$
\begin{gathered}
\left(x_{n}\right) \text { is a nondecreasing sequence in } A \\
\text { such that } x_{n} \longrightarrow x \text {; then } x_{n} \leq x . \\
\left(y_{n}\right) \text { is a nonincreasing sequence in } A \\
\text { such that } y_{n} \longrightarrow y \text {; then } y \leq y_{n} .
\end{gathered}
$$

Theorem 7. Assume the conditions (21) and $A_{0}$ is closed in $X$ instead of continuity of $F$ in Theorem 5; then the conclusion of Theorem 5 holds.

Proof. Following the proof of Theorem 5, there exist sequences $\left(x_{n}\right)$ and $\left(y_{n}\right)$ in $A$ satisfying the following conditions:

$$
\begin{aligned}
& d\left(x_{n+1}, F\left(x_{n}, y_{n}\right)\right)=d(A, B) \quad \text { with } x_{n} \leq x_{n+1}, \forall n \in \mathbb{N}, \\
& d\left(y_{n+1}, F\left(y_{n}, x_{n}\right)\right)=d(A, B) \quad \text { with } y_{n} \geq y_{n+1}, \forall n \in \mathbb{N} .
\end{aligned}
$$

Moreover, $\left(x_{n}\right)$ converges to $x$ and $y_{n}$ converges to $y$ in $A$. From (21), we get $x_{n} \leq x$ and $y_{n} \geq y$. Note that the sequences $\left(x_{n}\right)$ and $\left(y_{n}\right)$ are in $A_{0}$ and $A_{0}$ is closed. Therefore, $(x, y) \in A_{0} \times A_{0}$. Since $F\left(A_{0} \times A_{0}\right) \subseteq B_{0}$, there exists $F(x, y)$ and $F(y, x)$ are in $B_{0}$. Therefore, there exists $\left(x^{*}, y^{*}\right) \in$ $A_{0} \times A_{0}$ such that

$$
\begin{aligned}
& d\left(x^{*}, F(x, y)\right)=d(A, B), \\
& d\left(y^{*}, F(y, x)\right)=d(A, B) .
\end{aligned}
$$

Since $x_{n} \leq x$ and $y_{n} \geq y$. By using $F$ is proximally coupled contraction for (22) and (24) also for (25) and (23), we get

$$
\begin{array}{ll}
d\left(x_{n+1}, x^{*}\right) \leq \frac{k}{2}\left[d\left(x_{n}, x\right)+d\left(y_{n}, y\right)\right], & \forall n, \\
d\left(y^{*}, y_{n+1}\right) \leq \frac{k}{2}\left[d\left(y, y_{n}\right)+d\left(x, x_{n}\right)\right], & \forall n .
\end{array}
$$

Since $x_{n} \rightarrow x$ and $y_{n} \rightarrow y$, by taking limit on the above two inequality, we get $x=x^{*}$ and $y=y^{*}$. Consequently the result follows.

Corollary 8. Assume the conditions (21) instead of continuity of F in Corollary 6; then the conclusion of Corollary 6 holds.

Now, we present an example where it can be appreciated that hypotheses in Theorems 5 and 7 do not guarantee uniqueness of the coupled best proximity point.

Example 9. Let $X=\{(0,1),(1,0),(-1,0),(0,-1)\} \subset \mathbb{R}^{2}$ and consider the usual order $(x, y) \preceq(z, t) \Leftrightarrow x \leq z$ and $y \leq t$.

Thus, $(X, \preceq)$ is a partially ordered set. Besides, $\left(X, d_{2}\right)$ is a complete metric space considering $d_{2}$ the euclidean metric. Let $A=\{(0,1),(1,0)\}$ and $B=\{(0,-1),(-1,0)\}$ be closed subsets of $X$. Then, $d(A, B)=\sqrt{2}, A=A_{0}$ and $B=B_{0}$. Let $F$ : $A \times A \rightarrow B$ be defined as $F\left(\left(x_{1}, x_{2}\right),\left(y_{1}, y_{2}\right)\right)=\left(-x_{2},-x_{1}\right)$. Then, it can be seen that $F$ is continuous such that $F\left(A_{0} \times\right.$ $\left.A_{0}\right) \subseteq B_{0}$. The only comparable pairs of points in $A$ are $x \preceq x$ for $x \in A$; hence proximal mixed monotone property and proximally coupled contraction on $A$ are satisfied trivially.

It can be shown that the other hypotheses of the theorem are also satisfied. However, $F$ has three coupled best proximity points $((0,1),(0,1)),((0,1),(1,0))$, and $((1,0),(1,0))$.

One can prove that the coupled best proximity point is in fact unique, provided that the product space $A \times A$ endowed with the partial order mentioned earlier has the following property:

Every pair of elements has either a lower bound

or an upper bound.

It is known that this condition is equivalent to the following:

For every pair of $(x, y),\left(x^{*}, y^{*}\right) \in A \times A$, there exists $\left(z_{1}, z_{2}\right)$ in $A \times A$.

that is comparable to $(x, y),\left(x^{*}, y^{*}\right)$. 
Theorem 10. In addition to the hypothesis of Theorem 5 (resp., Theorem 7$)$, suppose that for any two elements $(x, y)$ and $\left(x^{*}, y^{*}\right)$ in $A_{0} \times A_{0}$,

$$
\begin{aligned}
& \text { there exists }\left(z_{1}, z_{2}\right) \in A_{0} \times A_{0} \\
& \text { such that }\left(z_{1}, z_{2}\right) \text { is comparable to }(x, y),\left(x^{*}, y^{*}\right) \text {; }
\end{aligned}
$$

then $F$ has a unique coupled best proximity point.

Proof. From Theorem 5 (resp., Theorem 7), the set of coupled best proximity points of $F$ is nonempty. Suppose that there exist $(x, y)$ and $\left(x^{*}, y^{*}\right)$ in $A \times A$ which are coupled best proximity points. That is,

$$
\begin{gathered}
d(x, F(x, y))=d(A, B), \quad d(y, F(y, x))=d(A, B), \\
d\left(x^{*}, F\left(x^{*}, y^{*}\right)\right)=d(A, B), \\
d\left(y^{*}, F\left(y^{*}, x^{*}\right)\right)=d(A, B) .
\end{gathered}
$$

We distinguish two cases.

Case 1. Suppose that $(x, y)$ is comparable. Let $(x, y)$ be comparable to $\left(x^{*}, y^{*}\right)$ with respect to the ordering in $A \times A$. Apply $F$ as proximally coupled contraction to $d(x, F(x, y))=$ $d(A, B)$ and $d\left(x^{*}, F\left(x^{*}, y^{*}\right)\right)=d(A, B)$, there exists $k \in(0,1)$ such that

$$
d\left(x, x^{*}\right) \leq \frac{k}{2}\left[d\left(x, x^{*}\right)+d\left(y, y^{*}\right)\right]
$$

Similarly, one can prove that

$$
d\left(y, y^{*}\right) \leq \frac{k}{2}\left[d\left(y, y^{*}\right)+d\left(x, x^{*}\right)\right]
$$

Adding (31) and (32), we get

$$
d\left(x, x^{*}\right)+d\left(y, y^{*}\right) \leq k\left[d\left(x, x^{*}\right)+d\left(y, y^{*}\right)\right] .
$$

This implies that $d\left(x, x^{*}\right)+d\left(y, y^{*}\right)=0$; hence $x=x^{*}$ and $y=y^{*}$.

Case 2. Suppose that $(x, y)$ is not comparable. Let $(x, y)$ be noncomparable to $\left(x^{*}, y^{*}\right)$; then there exists $\left(u_{1}, v_{1}\right) \in A_{0} \times$ $A_{0}$ which is comparable to $(x, y)$ and $\left(x^{*}, y^{*}\right)$.

Since $F\left(A_{0} \times A_{0}\right) \subseteq B_{0}$, there exists $\left(u_{2}, v_{2}\right) \in A_{0} \times A_{0}$ such that $d\left(u_{2}, F\left(u_{1}, v_{1}\right)\right)=d(A, B)$ and $d\left(v_{2}, F\left(v_{1}, u_{1}\right)\right)=d(A, B)$. Without loss of generality assume that $\left(u_{1}, v_{1}\right) \leq(x, y)$ (i.e., $x \geq u_{1}$ and $y \leq v_{1}$.) Note that $\left(u_{1}, v_{1}\right) \leq(x, y)$ implies that $(y, x) \leq\left(v_{1}, u_{1}\right)$. From Lemmas 2 and 3 , we get

$$
\left.\begin{array}{rr}
u_{1} \leq x, & v_{1} \geq y \\
d\left(u_{2}, F\left(u_{1}, v_{1}\right)\right)=d(A, B) \\
d(x, F(x, y))=d(A, B)
\end{array}\right\} \Longrightarrow u_{2} \leq x,
$$

From the above two inequalities, we obtain $\left(u_{2}, v_{2}\right) \leq(x, y)$. Continuing this process, we get sequences $\left\{u_{n}\right\}$ and $\left\{v_{n}\right\}$ such that $d\left(u_{n+1}, F\left(u_{n}, v_{n}\right)\right)=d(A, B)$ and $d\left(v_{n+1}, F\left(v_{n}, u_{n}\right)\right)=$ $d(A, B)$ with $\left(u_{n}, v_{n}\right) \leq(x, y) \forall n \in \mathbb{N}$. By using that $F$ is a proximally coupled contraction, we get

$$
\begin{gathered}
u_{n} \leq x, \quad v_{n} \geq y \\
d\left(u_{n+1}, F\left(u_{n}, v_{n}\right)\right)=d(A, B) \\
d(x, F(x, y))=d(A, B) \\
\Downarrow \\
d\left(u_{n+1}, x\right) \leq \frac{k}{2}\left[d\left(u_{n}, x\right)+d\left(v_{n}, y\right)\right], \quad \forall n \in \mathbb{N} .
\end{gathered}
$$

Similarly, we can prove that

$$
\begin{gathered}
y \leq v_{n}, \quad x \geq u_{n} \\
d(y, F(y, x))=d(A, B) \\
d\left(v_{n+1}, F\left(v_{n}, u_{n}\right)\right)=d(A, B)
\end{gathered}
$$$$
\Downarrow
$$

$$
d\left(y, v_{n+1}\right) \leq \frac{k}{2}\left[d\left(y, v_{n}\right)+d\left(x, u_{n}\right)\right], \quad \forall n \in \mathbb{N} .
$$

Adding (35) and (36), we obtain

$$
\begin{gathered}
d\left(u_{n+1}, x\right)+d\left(y, v_{n+1}\right) \leq k\left[d\left(u_{n}, x\right)+d\left(v_{n}, y\right)\right] . \\
d\left(u_{n+1}, x\right)+d\left(y, v_{n+1}\right) \\
\leq k\left[d\left(u_{n}, x\right)+d\left(v_{n}, y\right)\right] \\
\leq k^{2}\left[d\left(u_{n-1}, x\right)+d\left(v_{n-1}, y\right)\right] \\
\quad \ldots \\
\leq k^{n+1}\left[d\left(u_{0}, x\right)+d\left(v_{0}, y\right)\right] .
\end{gathered}
$$

As $n \rightarrow \infty$, we get $d\left(u_{n+1}, x\right)+d\left(y, v_{n+1}\right) \rightarrow 0$, so that $u_{n} \rightarrow x$ and $v_{n} \rightarrow y$.

Analogously, one can prove that $u_{n} \rightarrow x^{*}$ and $v_{n} \rightarrow y^{*}$. Therefore, $x=x^{*}$ and $y=y^{*}$. Hence the proof is completed.

Example 11. Let $X=\mathbb{R}$ be endowed with usual metric, and with the usual order in $\mathbb{R}$.

Suppose that $A=[1,2]$ and $B=[-2,-1]$. Then $A$ and $B$ are nonempty closed subsets of $X$ and $A_{0}=1$ and $B_{0}=-1$. Also note that $d(A, B)=2$.

Now consider the function $F: A \times A \rightarrow B$ defined as

$$
F(x, y)=\frac{-x-y-2}{4}
$$

Then it can be seen that $F$ is continuous and $F(1,1)=-1$. Hence, $F\left(A_{0} \times A_{0}\right) \subseteq B_{0}$. It is easy to see that other hypotheses of the Theorem 10 are also satisfied. Further, it is easy to see that $(1,1)$ is the unique element satisfying the conclusion of Theorem 10.

The following result, due to Fan [7], is a corollary Theorem 10 by taking $A=B$. 
Corollary 12. In addition to the hypothesis of Corollary 6 (resp., Corollary 8), suppose that for any two elements $(x, y)$ and $\left(x^{*}, y^{*}\right)$ in $A \times A$,

$$
\begin{aligned}
& \text { there exists }\left(z_{1}, z_{2}\right) \in A \times A \\
& \text { such that }\left(z_{1}, z_{2}\right) \text { is comparable to }(x, y),\left(x^{*}, y^{*}\right) \text {; }
\end{aligned}
$$

then $F$ has a unique coupled fixed point.

\section{Conflict of Interests}

The authors declare that there is no conflict of interests regarding the publication of this paper.

\section{Acknowledgments}

This research Dr. K. Sitthithakerngkiet was funded by King Mongkut's University of Technology North Bangkok (Contract no. KMUTNB-GEN-57-19). Moreover, the third author was supported by the Higher Education Research Promotion and National Research University Project of Thailand, Office of the Higher Education Commission (NRU2557).

\section{References}

[1] S. Banach, "Sur les opérations dans les ensembles abstraits et leurs applications auxéquations intégrales," Fundamenta Mathematicae, vol. 3, pp. 133-181, 1922.

[2] A. D. Arvanitakis, "A proof of the generalized Banach contraction conjecture," Proceedings of the American Mathematical Society, vol. 131, no. 12, pp. 3647-3656, 2003.

[3] B. S. Choudhury and K. Das, "A new contraction principle in menger spaces," Acta Mathematica Sinica, vol. 24, no. 8, pp. 1379-1386, 2008.

[4] T. Suzuki, "A generalized banach contraction principle that characterizes metric completeness," Proceedings of the American Mathematical Society, vol. 136, no. 5, pp. 1861-1869, 2008.

[5] H. Alikhani, D. Gopal, M. A. Miandaragh, Sh. Rezapour, and N. Shahzad, "Some endpoint results for $\beta$-generalized weak contractive multifunctions," The Scientific World Journal, vol. 2013, Article ID 948472, 7 pages, 2013.

[6] P. Kumam, F. Rouzkard, M. Imdad, and D. Gopal, "Fixed point theorems on ordered metric spaces through a rational contraction," Abstract and Applied Analysis, vol. 2013, Article ID 206515, 9 pages, 2013.

[7] K. Fan, "Extensions of two fixed point theorems of F. E. Browder," Mathematische Zeitschrift, vol. 112, no. 3, pp. 234-240, 1969.

[8] M. De la Sen and R. P. Agarwal, "Some fixed point-type results for a class of extended cyclic self-mappings with a more general contractive condition," Fixed Point Theory and Applications, vol. 2011, article 59, 2011.

[9] P. Kumam, P. Salimi, and C. Vetro, "Best proximity point results for modified -proximal C-contraction mappings," Fixed Point Theory and Applications, vol. 2014, article 99, 2014.

[10] P. Kumam, H. Aydi, E. Karapinar, and W. Sintunavarat, "Best proximity points and extension of Mizoguchi-Takahashi's fixed point theorems," Fixed Point Theory and Applications, vol. 2013, article 242, 2013.
[11] P. Kumam and A. Roldn-Lpez-de-Hierro, "On existence and uniqueness of g-best proximity points under $(\varphi, \theta, \alpha, g)$-contractivity conditions and consequences," Abstract and Applied Analysis, vol. 2014, Article ID 234027, 14 pages, 2014.

[12] C. di Bari, T. Suzuki, and C. Vetro, "Best proximity points for cyclic Meir-Keeler contractions," Nonlinear Analysis: Theory, Methods and Applications, vol. 69, no. 11, pp. 3790-3794, 2008.

[13] A. A. Eldred and P. Veeramani, "Existence and convergence of best proximity points," Journal of Mathematical Analysis and Applications, vol. 323, no. 2, pp. 1001-1006, 2006.

[14] M. A. Al-Thagafi and N. Shahzad, "Convergence and existence results for best proximity points," Nonlinear Analysis: Theory, Methods and Applications, vol. 70, no. 10, pp. 3665-3671, 2009.

[15] S. Sadiq Basha and P. Veeramani, "Best proximity pair theorems for multifunctions with open fibres," Journal of Approximation Theory, vol. 103, no. 1, pp. 119-129, 2000.

[16] W. K. Kim and K. H. Lee, "Existence of best proximity pairs and equilibrium pairs," Journal of Mathematical Analysis and Applications, vol. 316, no. 2, pp. 433-446, 2006.

[17] W. A. Kirk, S. Reich, and P. Veeramani, "Proximinal retracts and best proximity pair theorems," Numerical Functional Analysis and Optimization, vol. 24, no. 7-8, pp. 851-862, 2003.

[18] V. Sankar Raj, "A best proximity point theorem for weakly contractive non-self-mappings," Nonlinear Analysis: Theory, Methods and Applications, vol. 74, no. 14, pp. 4804-4808, 2011.

[19] E. Karapınar, V. Pragadeeswarar, and M. Marudai, "Best proximity point for generalized proximal weak contractions in complete metric space," Journal of Applied Mathematics, vol. 2014, Article ID 150941, 6 pages, 2014

[20] M. Jleli and B. Samet, "Remarks on the paper: best proximity point theorems: An exploration of a common solution to approximation and optimization problems," Applied Mathematics and Computation, vol. 228, pp. 366-370, 2014.

[21] S. S. Basha, "Discrete optimization in partially ordered sets," Journal of Global Optimization, vol. 54, no. 3, pp. 511-517, 2012.

[22] A. Abkar and M. Gabeleh, "Best proximity points for cyclic mappings in ordered metric spaces," Journal of Optimization Theory and Applications, vol. 150, no. 1, pp. 188-193, 2011.

[23] A. Abkar and M. Gabeleh, "Generalized cyclic contractions in partially ordered metric spaces," Optimization Letters, vol. 6, no. 8, pp. 1819-1830, 2012.

[24] W. Sintunavarat and P. Kumam, "Coupled best proximity point theorem in metric spaces," Fixed Point Theory and Applications, vol. 2012, article 93, 2012.

[25] V. Pragadeeswarar and M. Marudai, "Best proximity points: approximation and optimization in partially ordered metric spaces," Optimization Letters, vol. 7, pp. 1883-1892, 2013.

[26] V. Pragadeeswarar and M. Marudai, "Best proximity points for generalized proximal weak contractions in partially ordered metric spaces," Optimization Letters, 2013.

[27] C. Mongkolkeha and P. Kumam, "Best proximity point Theorems for generalized cyclic contractions in ordered metric Spaces," Journal of Optimization Theory and Applications, vol. 155, pp. 215-226, 2012.

[28] W. Sanhan, C. Mongkolkeha, and P. Kumam, "Generalized proximal -contraction mappings and Best proximity points," Abstract and Applied Analysis, vol. 2012, article 42, 2012.

[29] C. Mongkolkeha and P. Kumam, "Best proximity points for asymptotic proximal pointwise weaker Meir-Keeler-type contraction mappings," Journal of the Egyptian Mathematical Society, vol. 21, no. 2, pp. 87-90, 2013. 
[30] C. Mongkolkeha and P. Kumam, "Some common best proximity points for proximity commuting mappings," Optimization Letters, vol. 7, no. 8, pp. 1825-1836, 2013.

[31] C. Mongkolkeha, Y. J. Cho, and P. Kumam, "Best proximity points for generalized proxinal C-Contraction mappings in metric spaces with partial orders," Journal of Inequalities and Applications, vol. 2013, article 94, 2013.

[32] C. Mongkolkeha, Y. J. Cho, and P. Kumam, "Best proximity points for Geraghty's proximal contraction mappings," Fixed Point Theory and Applications, vol. 2013, article 180, 2013.

[33] C. Mongkolkeha, C. Kongban, and P. Kumam, "The existence and uniqueness of best proximity point theorems for generalized almost contraction," Abstract and Applied Analysis, vol. 2014, Article ID 813614, 11 pages, 2014.

[34] T. G. Bhaskar and V. Lakshmikantham, "Fixed point theorems in partially ordered metric spaces and applications," Nonlinear Analysis: Theory, Methods and Applications, vol. 65, no. 7, pp. 1379-1393, 2006.

[35] V. Lakshmikantham and L. Ćirić, "Coupled fixed point theorems for nonlinear contractions in partially ordered metric spaces," Nonlinear Analysis: Theory, Methods and Applications, vol. 70, no. 12, pp. 4341-4349, 2009.

[36] N. V. Luong and N. X. Thuan, "Coupled fixed point theorems for mixed monotone mappings and an application to integral equations," Computers and Mathematics with Applications, vol. 62, no. 11, pp. 4238-4248, 2011.

[37] W. Shatanawi, "Partially ordered cone metric spaces and coupled fixed point results," Computers and Mathematics with Applications, vol. 60, no. 8, pp. 2508-2515, 2010. 


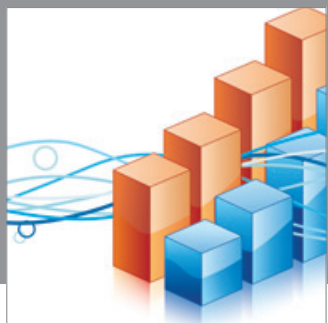

Advances in

Operations Research

mansans

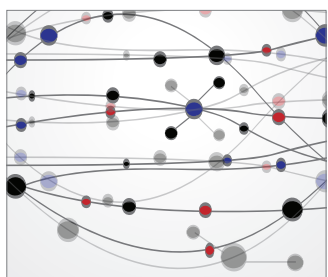

The Scientific World Journal
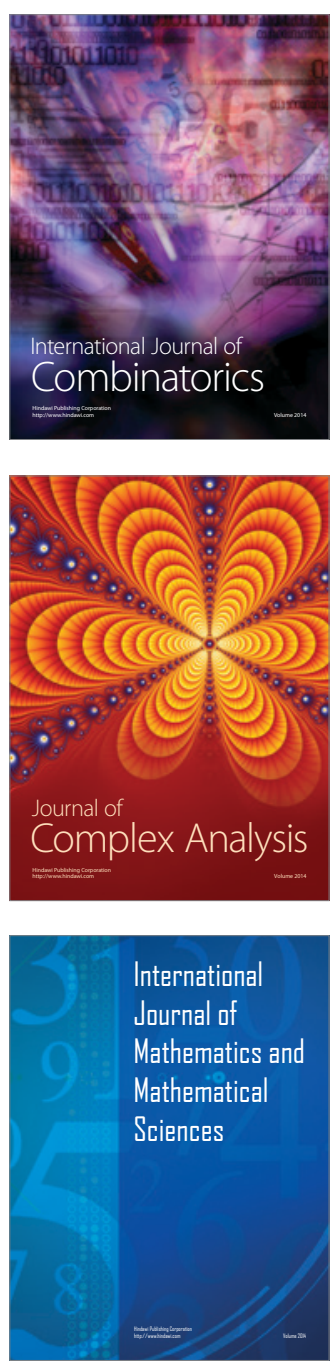
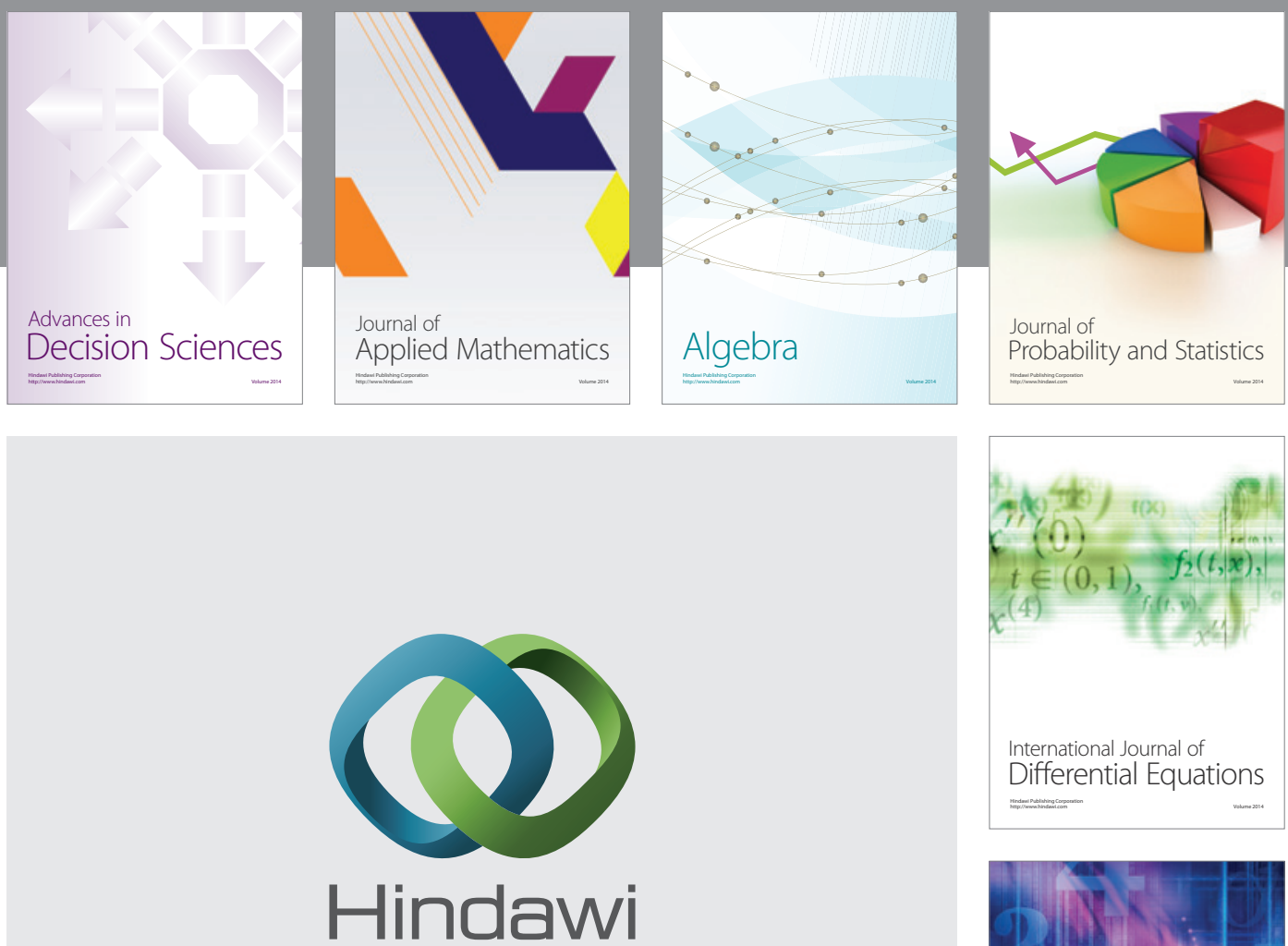

Submit your manuscripts at http://www.hindawi.com
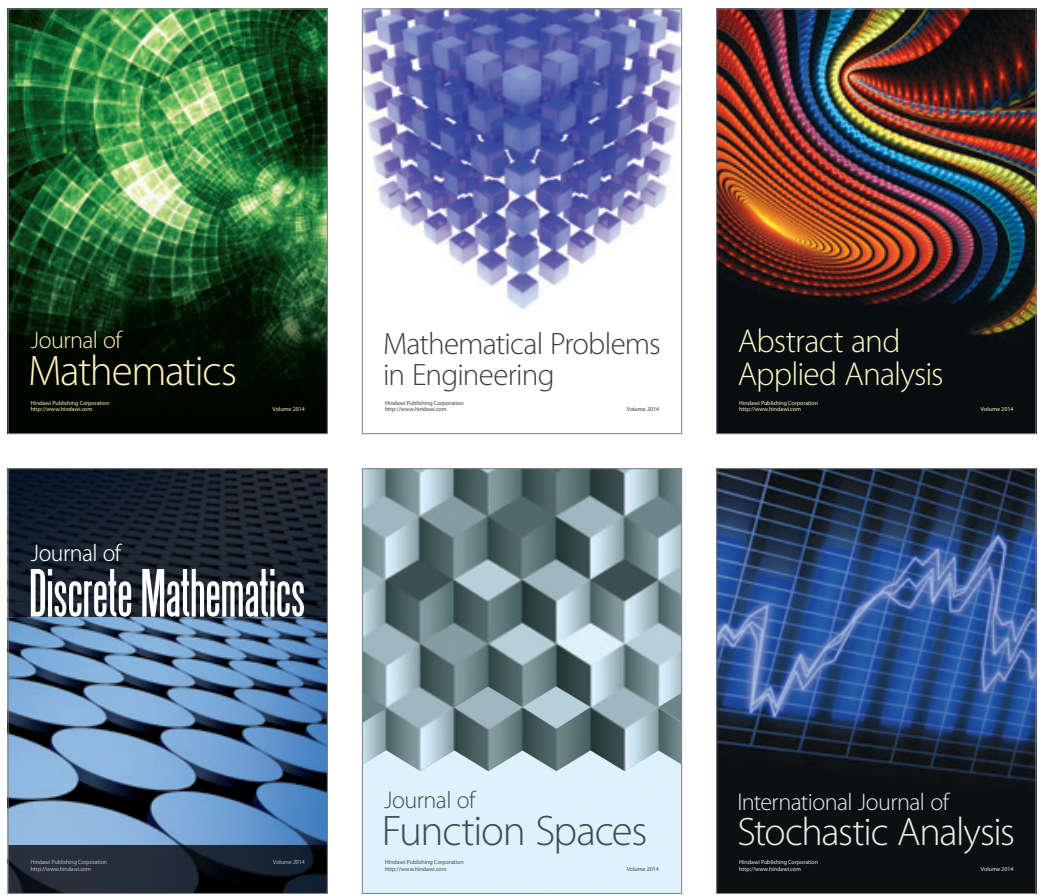

Journal of

Function Spaces

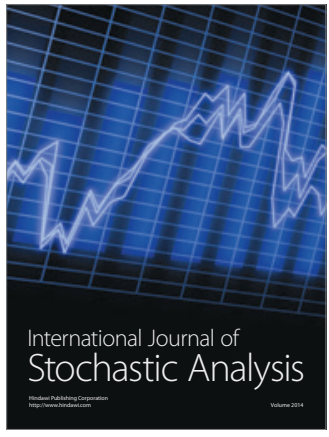

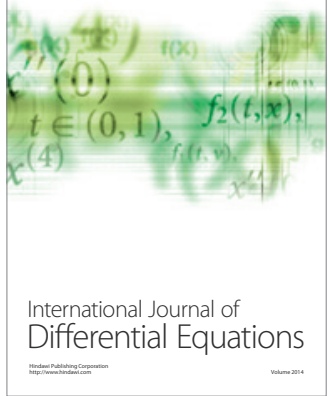
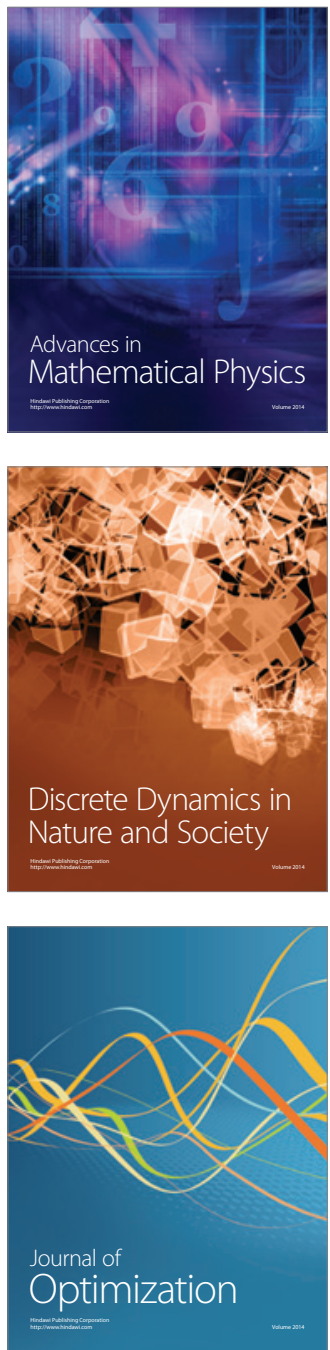